\title{
Three-dimensional numerical analysis of a joint bonded reinforced with silica nanoparticles $\left(\mathrm{SiO}_{2}\right)$
}

\author{
Hadj Boulenouar Rachid, Boutabout Benali \\ Laboratory of Mechanics Physics of Materials (LMPM), Djillali Liabes University, Department of Mechanical Engineering, Sidi \\ Bel Abbes, Algeria \\ r.hadjboulenouan@gmail.com,bboutabout@yahoo.fr
}

\section{Djebbar Noureddine}

Laboratory of Mechanics Physics of Materials (LMPM), Hassiba Benbouali University, Department of Mechanical Engineering, Chlef, Algeria.

djebbarnoun@yahoo.fr, bttps://orcid.org/0000-0002-6496-7996

\begin{abstract}
Nanostructured adhesives may be defined as those materials whose elements imbedded in an epoxy matrix have dimensions in the 1 to 100 $\mathrm{nm}$ range. One of the most interesting aspects of ceramic nanoparticles is that their mechanical properties depend strongly upon the particle size and shape. Silica nanoparticles $\left(\mathrm{SiO}_{2}\right)$ have different physical and mechanical properties from bulk ceramics. The aim of the present study is to investigate the effect of the nanoparticles rate on the equivalent stress, peeling stress and shear stress as well as the strains developed in the adhesive joint. Three-dimensional finite element models of adhesive joint were developed to determine the stress intensity as well as strain with different nanoparticles rate in the epoxy resin. Dispersion of nanoparticles with different percent in the epoxy resin allows for reinforcing the adhesive. Polymer embedded silica nanoparticles $\left(\mathrm{SiO}_{2}\right)$ proved to be highly effective.
\end{abstract}

KEYwords. Epoxy, Finite Element Method, Silica Nanoparticles $\mathrm{SiO}_{2}$, Stress, Strain.

\section{OPEN@ACCESS}

Citation: Hadj Boulenouar, R., Boutabout, B., Djebbar, N., Three-dimensional numerical analysis of a joint bonded reinforced with silica nanoparticles $\left(\mathrm{SiO}_{2}\right)$, Frattura ed Integrità Strutturale, 52 (2020) 128-136.

Received: 09.11.2019

Accepted: 02.01 .2020

Published: 01.04.2020

Copyright: (C) 2020 This is an open access article under the terms of the CC-BY 4.0, which permits unrestricted use, distribution, and reproduction in any medium, provided the original author and source are credited.

\section{INTRODUCTION}

7 here is an increasing interest in polymer/silica nanocomposites for the developments of new materials with improved thermal and mechanical properties [1-3]. Polymer nanocomposites are among the most promising materials. The incorporation of a small fraction of nanoparticles into a polymer matrix not only leads to dramatically reinforced mechanical properties [4], but also endows the material with flame-retardant [5, 6], conductivity [7, 8], gas-barrier [9], and optical properties [10, 11], among others. However, these enhanced properties depend strongly on nanoparticle dispersion and the interfacial interactions between the nanoparticles and the polymer matrices [12-15]. Polymers are used for high-technology application areas such as coatings, electrical appliances, adhesives, automotive and aerospace industries 
[16-18]. The Polymeric nanocomposites are usually defined as a combination of a polymer matrix and nanometric particles [19]. The possibilities of improving the mechanical or thermal properties and the development of new materials by nanoparticles have found applications in academia and industry. Several experimental and theoretical studies have been carried out on the mechanical properties of microphones and nanocomposites. Many papers report improved polymer properties more efficiently using nanoparticles than with microparticles [20]. The epoxy resin is a rigid polymer with good chemical stability, mechanical and electrical properties. It is widely used as a matrix of composite materials reinforced by fillers and as adhesives [21, 22]. When cured, the epoxy is amorphous and highly cross-linked (i.e. thermosetting polymers). This microstructure provides many useful properties for engineering applications, such as a modulus of elasticity, high and failure resistance, low creep, and good performance at high temperatures [23]. However, the structure of the epoxy also leads to very undesirable properties when it is a relatively fragile material, with a low resistance to initiation and growth of the cracks. The thermal loading effect on free vibration characteristics of carbon nanotubes (CNTs) with multiple cracks has been studied [24]. The nanoparticles have been widely used in epoxy matrix composites as reinforcements. Compared to micro-loaded composites with nanoparticles open up a wide range of potential new applications, due to their improved engineering properties, such as stiffness and hardness, and other beneficial functions such as the barrier against nanoparticles, humidity and flame retardancy [25]. The objective of this work is to analyze by three-dimensional finite element method using the Abaqus calculation code, the stress distribution of shear and peeling in the adhesive joint used to assembly two aluminum plates. Several parameters have been highlighted such as the stiffness of the nanostructured adhesive and their size, in order to see the effect of the silica nanoparticles' dispersion imbedded in the epoxy resin on the charge transferred in the adhesive layer.

\section{GEOMETRIC MODEL AND MECHANICAL PROPERTIES}

he adhesively bonded single-lap joint studied in the present work is shown in Fig. 1. The two adherends used were aluminum alloy plates (2024-T3) of dimensions $200 \mathrm{~mm}$ long, $20 \mathrm{~mm}$ wide, $2 \mathrm{~mm}$ thickness. The mechanical properties of the adherends were as follows: Poisson's ratio $\nu=0.33$, Young's modulus E $=69 \mathrm{GPa}$. The mechanical properties of the adhesives investigated were: Poisson's ratio $v_{\mathrm{ad}}=0.33$, Young's modulus $\mathrm{E}=3.5 \mathrm{GPa}[26]$.

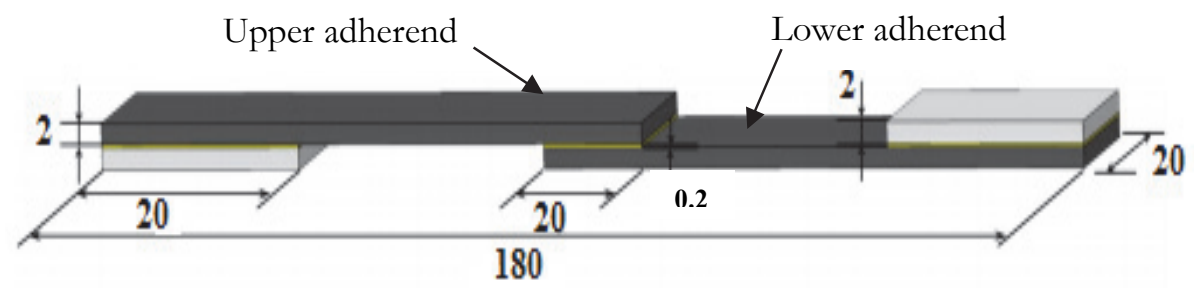

Figure 1: Geometrical model.

\section{BOUNDARY CONDITIONS}

chematic of the entire model (Fig. 2), including the fixed connection (zero displacement) at the left end, a distributed load of $40 \mathrm{MPa}$ was applied at the right end of the upper substrate in the $\mathrm{x}$-direction. The joint is oriented along the $\mathrm{x}, \mathrm{z}$ is the direction of the width and $\mathrm{y}$ is the direction normal to the joint plane.

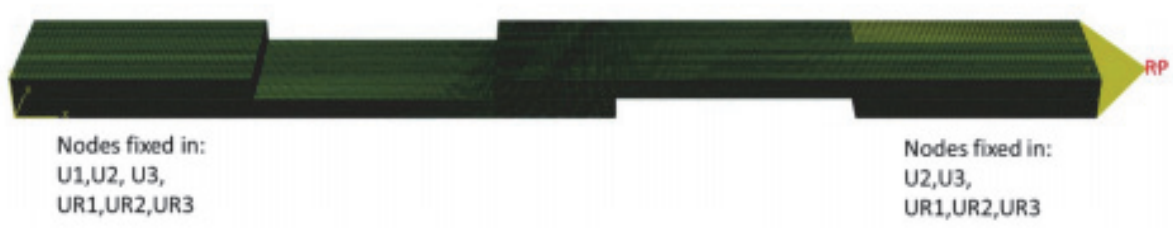

Figure 2: Boundary conditions for the symmetry FE model. 
In the case of FE analysis of adhesively bonded joints the thickness of adhesive layer is much smaller than that of the adherends. The FE mesh must accommodate both the small dimension of the adhesive layer and the larger dimension of the remainder of the whole model. It is essential to model the adhesive layer by a FE mesh which is smaller than the adhesive layer thickness. The result is that the FE mesh must be several orders of magnitude more refined in a very small region than is needed in the rest of the joint. Thus the number of degrees of freedom in an adhesively bonded joint is rather high. It is also important that a smooth transition between the adherends and adhesive be provided for later distortion analysis. The original FE mesh is shown in Fig. 3. The FE mesh of the joint was created using the ABAQUS FEA pre-processing program. Most of the adherends and adhesive were modelled using the 20-node quadratic brick solid elements.

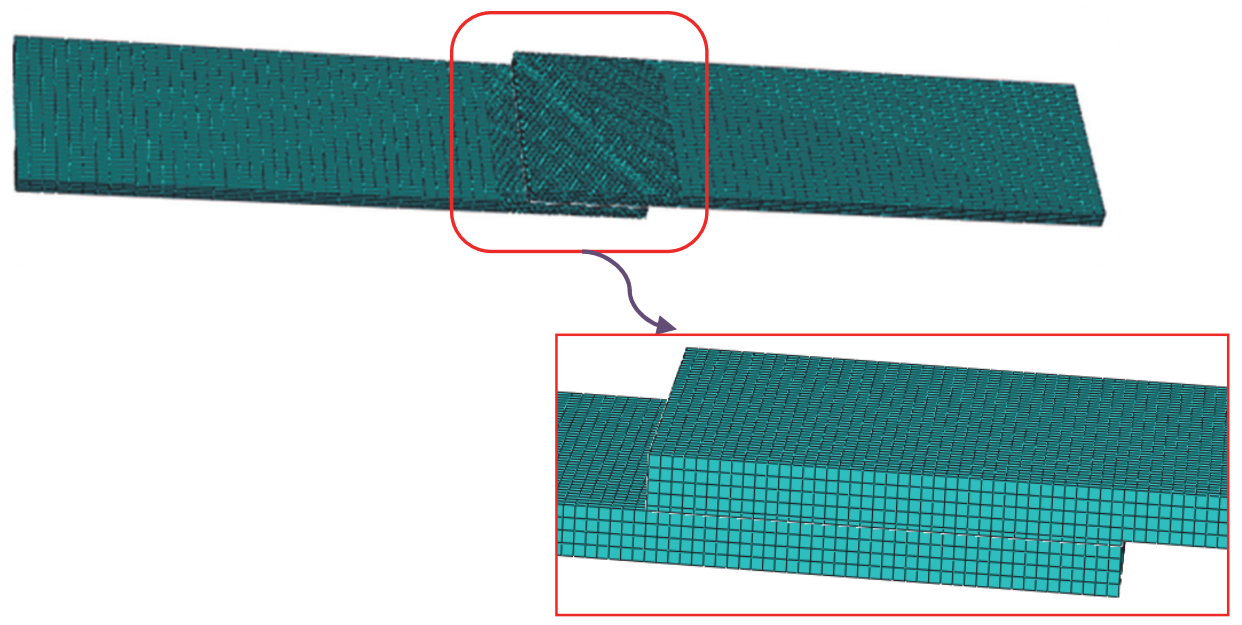

Figure 3: Mesh of the assembly.

\section{INVESTIGATED MATERIALS}

\section{Substrates}

wo substrates are made of a highly ductile 2024-T3 aluminum alloy, which gives the advantage of good solid state plastic deformation shaping properties, with low melting point, about $650{ }^{\circ} \mathrm{C}$. Alloy 2024 has better mechanical properties due to higher magnesium content. It has good resistance to toughness and crack propagation. The 2024 is widely used in aircraft construction.

\section{Adhesives}

The epoxy resin examined was a standard diglycidyl either of bisphenol A (DER331 resin, Dow Chemical Company) with an equivalent molecular weight of $187 \mathrm{~g} / \mathrm{mol}$. The nano $\mathrm{SiO}_{2}$ particles (3M Corporation) with an average particles size of $174 \mathrm{~nm}, 74 \mathrm{~nm}$ and $23 \mathrm{~nm}$ were surface modified by a sol-gel process to prevent agglomeration and to maintain a narrow particles size distribution. The nanosilica particles were supplied as pre-mixed concentrates in a DGEBA epoxy resin. Piperidine (Sigma-Aldrich) was used as the curing agent.

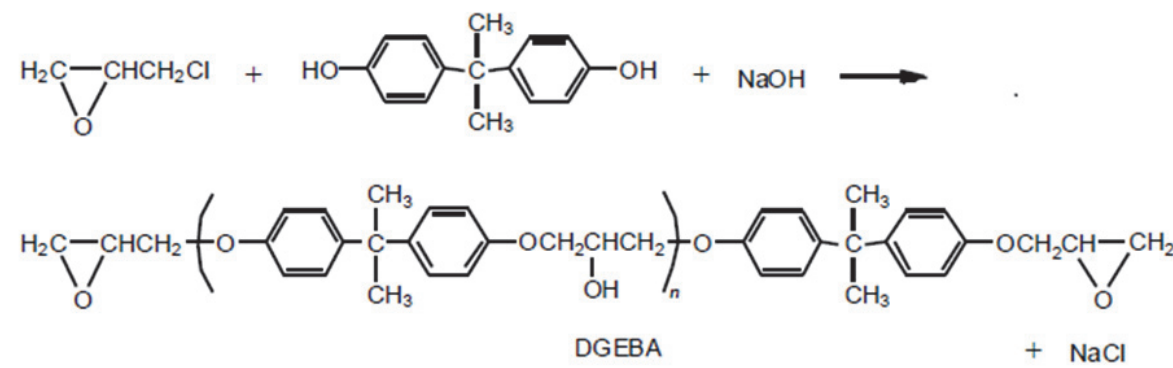

Figure 4: Synthesis of DGEBA. 


\begin{tabular}{cc}
\hline Properties & Epoxy \\
Viscosity $\left(\right.$ Pa.s) at $25 \mathrm{C}^{\circ}$ & $12000-13000$ \\
Density $\left(\mathrm{kg} / \mathrm{m}^{3}\right)$ & 1160 \\
Temperature distortion $\left({ }^{\circ} \mathrm{C}\right)$ & 50 \\
Modulus of elasticity $\mathrm{E}(\mathrm{GPa})$ & $2.4-5$ \\
Flexural strength $(\mathrm{MPa})$ & 60 \\
Tensile strength $(\mathrm{MPa})$ & 73 \\
Maximum elongation $(\%)$ & 4 \\
\hline
\end{tabular}

Table 1: Properties of epoxy resin [27].

\section{EFFECT OF NANOFILLERS ON THE EPOXY RESIN}

$\mathrm{T}$

he Young's modulus $\mathrm{E}$ of the nanocomposite materials were measured using dog-bone shaped tensile specimens [28]. The results are shown in Tab. 2 along with the standard deviation (calculated from at least five samples). The presence of the nanosilica particles increases the modulus, $\mathrm{E}$, of the nanocomposite; with the value of $\mathrm{E}$ increasing steadily as the weight \% of the silica phase is increased [29]. The effect of nanosilica particles content on the Young's modulus is depicted in Tab. 2 .

\begin{tabular}{ccc}
\hline $\begin{array}{c}\text { Nanosilica particles } \\
\text { sizes (nm) }\end{array}$ & Volume $\%)$ & E (GPa) \\
& & \\
unmodified & 0 & 3.50 \\
& & \\
\hline & 2.5 & 3.50 \\
& 5 & 3.62 \\
& 10 & 4.24 \\
& 15 & 4.56 \\
& 20 & 4.78 \\
& 25 & 5.22 \\
& 30 & 5.53 \\
\hline \multirow{2}{*}{74} & 2.5 & 3.67 \\
& 5 & 3.80 \\
& 10 & 4.15 \\
& 15 & 4.50 \\
& 20 & 4.76 \\
& 25 & 5.43 \\
& 30 & 5.60 \\
\hline \multirow{2}{*}{174} & 2.5 & 3.50 \\
& 5 & 3.62 \\
& 10 & 4.25 \\
& 15 & 4.60 \\
& 20 & 4.87 \\
& 25 & 5.35 \\
& 30 & 5.78 \\
\hline
\end{tabular}

Table 2: Values of nanosilica filled DGEBA as a function of filler content compared at different sizes of nanosilica particles [30]. 


\section{RESULTS AND DISCUSSION}

$\mathrm{I}$ $\mathrm{n}$ this work, the Abaqus calculation code is used to model the simple overlap joint, which is composed of two 2024 aluminum substrates and the epoxy resin loaded with nano-silica particles. Using the table, which shows the Young's modulus of the unfilled epoxy resin (EP), and then the same resin loaded with different percentages of the nano-silica particles.

\section{Effect of the rate of the nanoparticles on the stresses}

Figs. 5, 6 and 7 illustrate respectively the variation of the von Mises stress ( $\left.\sigma_{\text {Mises }}\right)$, the shear stress $\left(\sigma_{\mathrm{xy}}\right)$ and the peel stress $\left(\sigma_{\mathrm{yy}}\right)$ according to the overlap length, without and with nanoparticles and their diameters are equal to $23 \mathrm{~nm}$. The results are obtained numerically by the finite element method for three percentages of nanoparticles $(2.5 \%, 15 \%$ and $30 \%)$. Whatever the rate of the nanoparticles imbedded in the matrix, it is noted that the maximum stresses are located at two free ends of the bonded assembly. However, the minimum stresses are always at the assembly's core. The results obtained show that the curves of the stresses are almost similar because the rate of the nanoparticles is relatively smaller than the volume of the resin, it varies from $2.5 \%$ to $30 \%$. It is noted that increasing the rate of the nanoparticles leads to an increase in the maximum stress. It is observed that the value of the maximum stress is proportional to the quantities of nanoparticles imbedded in the adhesive matrix. The addition of inorganic spherical nanoparticles to polymer allows the modification of the polymer physical properties as well as the implementation of new features in the polymer matrix.

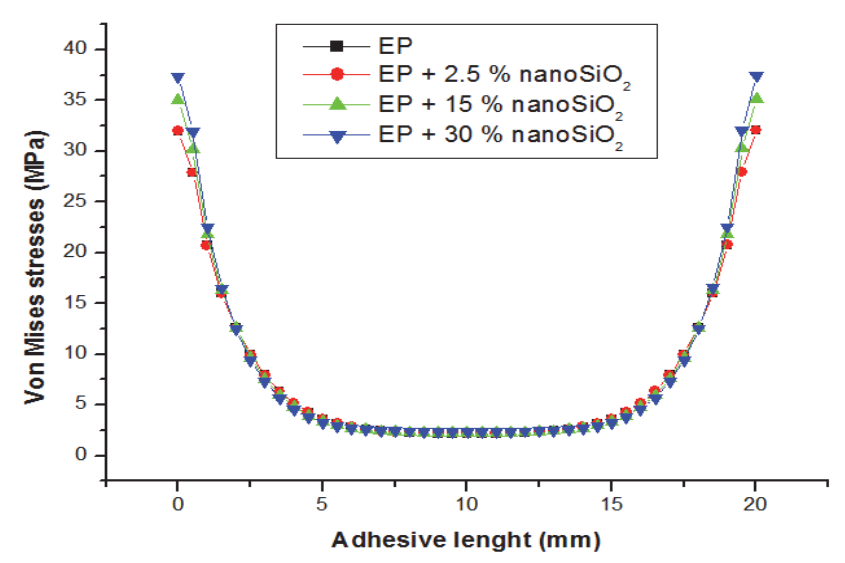

Figure 5: Variation of the Von Mises stress.

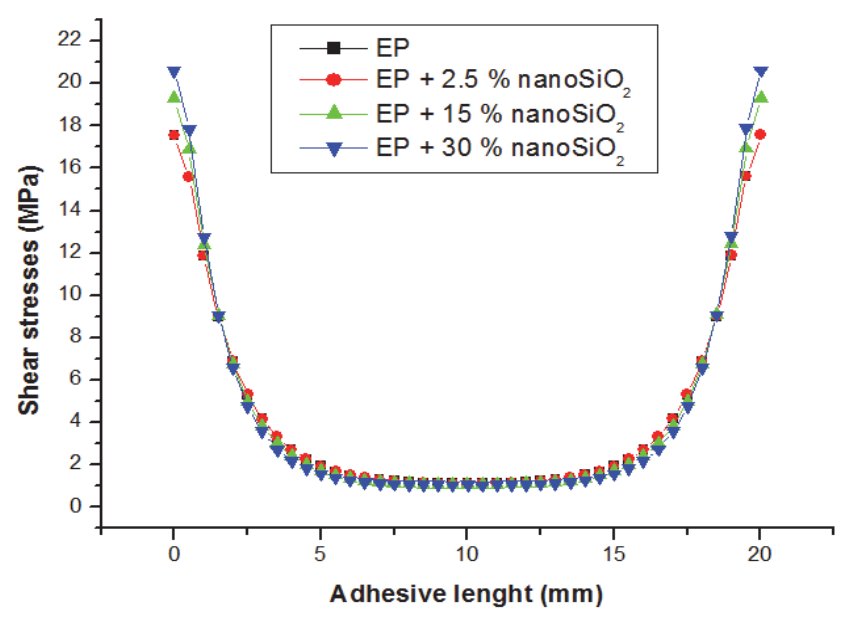

Figure 6: Variation of the Shear stress. 


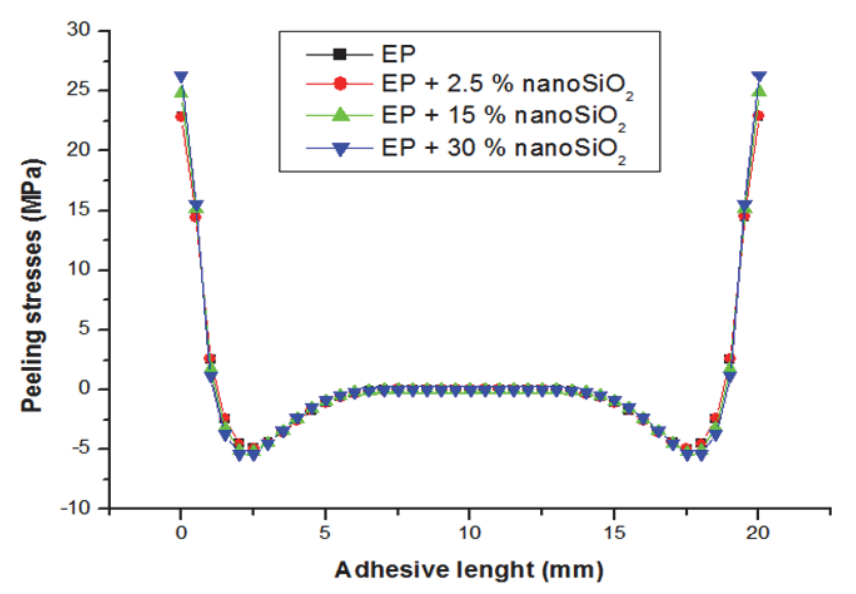

Figure 7: Variation of the Peel stress.

\section{Effect of the rate of the nanoparticles on the equivalent stress}

Fig. 8 represents the variation of the maximum value of the equivalent stress as a function of the rate of the nanoparticles for three diameters of nanoparticles. It is noted that whatever the size of the nanoparticles the maximum value of the equivalent stress varies proportionally to the rate of the nanoparticles added in the adhesive, which confirms the results obtained previously. It is also noted that increase the stress is due to an increase of the Young's modulus of the adhesive joint. The latter behaves like a brittle material whose Young's modulus increases with the rate of the nanoparticles added in the adhesive. It can be seen that whatever the percentage of silica nanoparticles, the difference between the von Mises stress, which corresponds to different diameters of the nanoparticles is relatively weak.

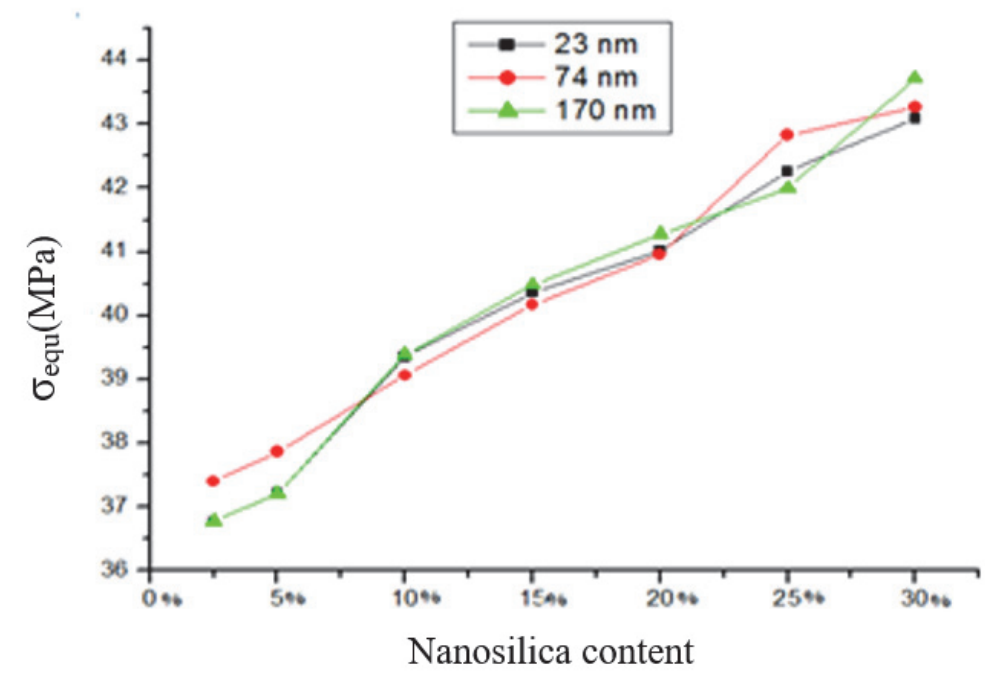

Figure 8: Variation of the equivalent stress as a function of the silica nanoparticles diameter.

\section{Effect of the rate of the nanoparticles on the strains}

Figs. 9, 10 and 11 show the variation of the strain $\left(\varepsilon_{\mathrm{xx}}, \varepsilon_{\mathrm{xy}}\right.$ and $\left.\varepsilon_{\mathrm{yy}}\right)$ according to the length of the adhesive joint without and with Silica nanoparticles whose diameter is equal to $23 \mathrm{~nm}$. The strain curves have been drawn for three percentages of Silica nanoparticles $(2.5 \%, 15 \%$ and $30 \%)$. It is noted that the maximum strains are located as the ends of the joint. It is noted that the strain depends on the rate of the nanoparticles in the epoxy matrix. The strain curve clearly shows that increasing silica nanoparticles leads to a decrease of the linear and angular strain. Indeed, reinforcement of the matrix by ceramic-type nanoparticles makes it possible to transform the resin into a brittle material with a weak strain. 


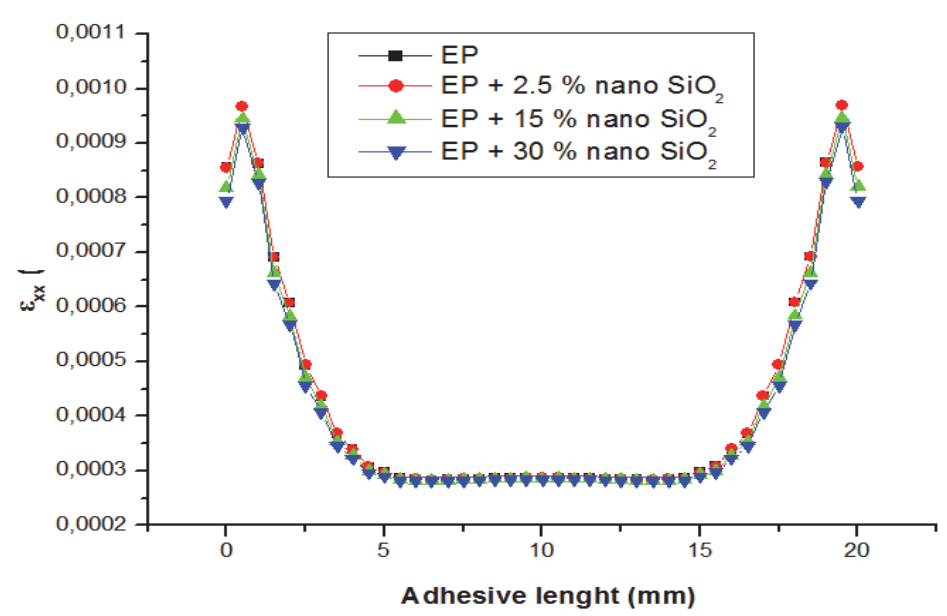

Figure 9: Variation of the strains $\left(\varepsilon_{\mathrm{xx}}\right)$.

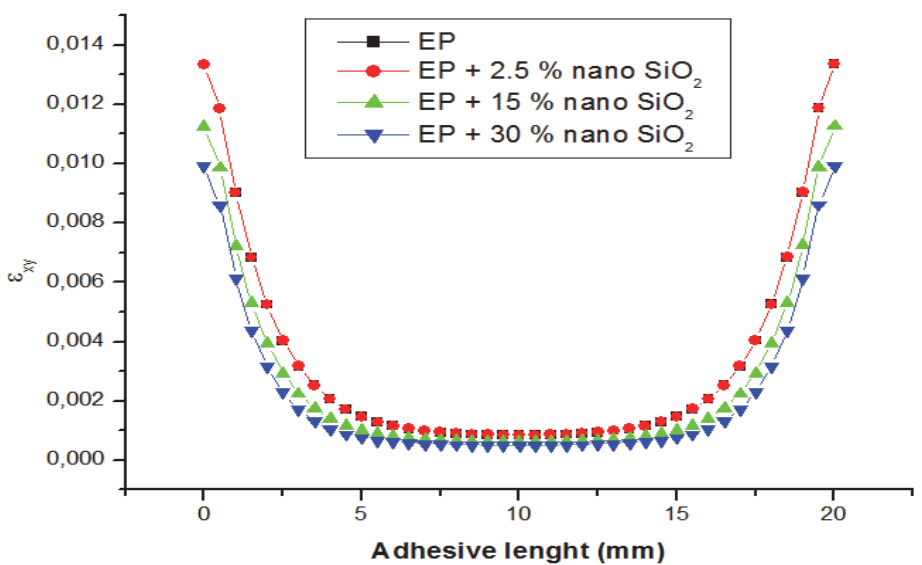

Figure 10: Variation of the strains $\left(\boldsymbol{\varepsilon}_{\mathrm{xy}}\right)$.

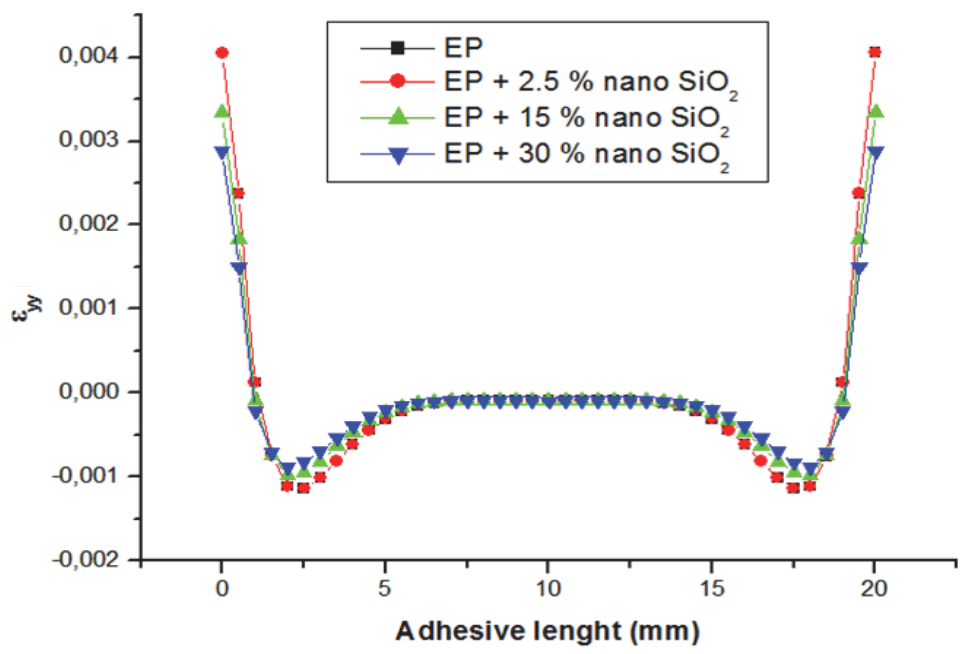

Figure 11: Variation of the strains $\left(\boldsymbol{\varepsilon}_{\mathrm{yy}}\right)$. 


\section{Effect of the diameter of silica nanoparticles on the strains}

Fig. 12 illustrates the variation of the maximum strain $(\varepsilon \max )$ as a function of the rate of the nanoparticles for three diameters $(23 \mathrm{~nm}, 74 \mathrm{~nm}, 170 \mathrm{~nm})$ of nanoparticles. It is noted that whatever the percentage of silica nanoparticles, the difference between the maximum strains, which correspond to different diameters of Silica nanoparticles, is relatively weak. In order, the obtained results show that the maximum strain is almost independent of the nanoparticles diameters.

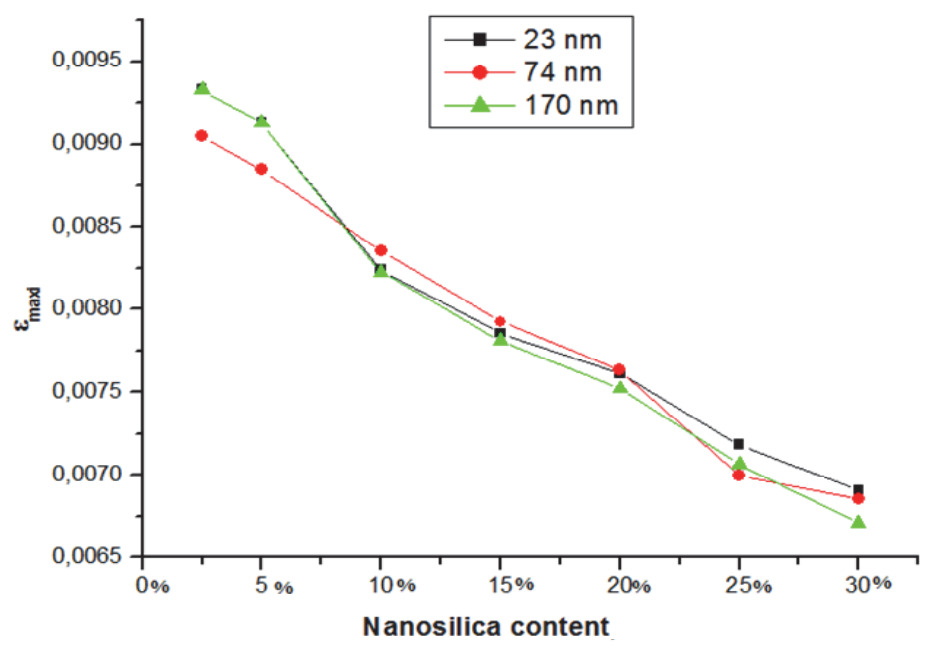

Figure 12: Variation of the maximum strain as a function of the diameter of silica nanoparticles.

\section{CONCLUSION}

$\mathrm{F}$ rom the results above, obtained by the three dimensional numerical analysis, one can draw the following conclusions: The mechanical properties of the adhesive reinforced by Silica nanoparticles, in particular, its Young's modulus depends on the rate of the nanoparticle.

Increasing the quantities of Silica nanoparticles in the matrix leads to increase the von Mises stress, shearing and peeling at both ends the recovery length.

A significant increase in the rate of the nanoparticles in the adhesive joint leads to a decrease in the maximum strains. Decreasing the deformations within the joint, that means that the reinforcement of this resin with different percentages of Silica nanoparticles to improve rigidity and its resistance to fracture. Whatever, the rate of Silica nanoparticles added in the adhesive the maximum strain and stress are almost independent of the nanoparticle size.

\section{REFERENCES}

[1] Knopp, D., Tang, D., Niessner, R. (2009). Review: bioanalytical applications of biomolecule- functionalized nanometer-sized doped silica particles, Anal. Chim. Act. 647, pp. 14-30.

[2] Kohut, A., Ranjan, S., Voronov, A., Peukert, W., Tokarev, V., Bednarska, O., Gevus, O., Voronov, S. (2006), Design of a new invertible polymer coating on a solid surface and its effect on dispersion colloidal stability, Langmuir 22, pp. 6498-6506.

[3] Zou, H., Wu, S., Shen, J. (2008). Polymer/silica nanocomposites: Preparation, characterization, properties, and applications. Chem. Rev, 108, pp. 3893-957.

[4] Song, P., Cao, Z., Cai, Y., Zhao, L., Fang, Z., Fu, S. (2011), Fabrication of exfoliated graphene-based polypropylene nanocomposites with enhanced mechanical and thermal properties. Polymer, 52, pp. 4001-10.

[5] Wang, X., Kalali, E.N., Wan, J., Wang, D. (2017). Carbon-family materials for flame retardant polymeric materials. Prog. Polym. Sci., 69, pp. 22-46. 
[6] Wang, D.Y., Leuteritz, A., Wang, Y.Z., Wagenknecht, U., Heinrich, G. (2010), Preparation and burning behaviors offlame retarding biodegradable poly (lactic acid) nanocomposite based on zinc aluminum layered double hydroxide. Polym. Degrad. Stab, 95, pp. 2474-24.

[7] Xu, X., Chen, J., Zhou, J., Li, B. (2018), Thermal conductivity of polymers and their nanocomposites. Adv. Mater,30.

[8] Gao, C., Zhang, S.M., Wang, F., Wen, B., Han, C.C., Ding, Y.F., et al. (2014), Graphene networks with low percolation threshold in ABS nanocomposites: Selective localization and electrical and rheological properties. ACS Appl. Mater. Interfaces, 6, pp. 12252-12260

[9] Cui, Y., Kundalwal, S.I., Kumar, S. (2016). Gas barrier performance of graphene/polymer nanocomposites. Carbon, 98, pp. 313-333.

[10] Pan, Z.B., Zhai, J.W., Shen, B. (2017). Multilayer hierarchical interfaces with high energy density in polymer nanocomposites composed of BaTiO3@TiO2@Al2O3 nanofibers. J. Mater. Chem. A, 5, pp. 15217-15226.

[11] Han, C.C., Wang, F., Gao, C., Liu, P., Ding, Y.F., Zhang, S.M., et al. (2015), Transparent epoxy-ZnO/CdS nanocomposites with tunable UV and blue light-shielding capabilities. J. Mater. Chem. C, 3, pp. 5065-5872.

[12] Kumar, S.K., Jouault, N., Benicewicz, B., Neely, T. (2013). Nanocomposites with polymer grafted nanoparticles. Macromolecules, 46, pp. 3199-3214.

[13] Khani, M.M., Woo, D., Mumpower, E.L., Benicewicz, B.C. (2017). Poly (alkyl methacrylate)-grafted silica nanoparticles in polyethylene nanocomposites. Polymer, 109, pp. 339-348.

[14] Kumar, S.K., Krishnamoorti, R. (2010). Nanocomposites: Structure, phase behavior, and properties. Ann.Rev. Chem. Biomol. Eng, 1, pp. 37-58.

[15] Ahmad, H.M. Y., Midhat, N. S. and Mohd, F. J. (2017), A review: Synthetic strategy control of magnetite nanoparticles production. Advances in Nano Research, 6 (1), pp. 1-19.

[16] Jiang, W., Jin, F. and Park, S. (2012). Thermo-mechanical behaviors of epoxy resins reinforced with nanoparticles $\mathrm{Al}_{2} \mathrm{O}_{3}$, Journal of Industrial and Engineering chemistry, 18 (2), pp. 594-596.

[17] McGrath, L., Parnas, R., King, S., Schroeder, J., Fischer, D. and Lenhart, J. (2008), Investigation of the thermal, mechanical, and fracture properties of alumina epoxy composites, Polymer, 49 (4), pp. 999-1014.

[18] Omrani, A. and Rostami, A. (2009), Understanding the effect of nano- $\mathrm{Al}_{2} \mathrm{O}_{3}$ addition upon the properties of epoxy based hybrid composites, Materials Science and Engineering: A, 517(1), pp. 185-190.

[19] Moreira, D.C, Sphaier, L.A., Reis, J.M.L and Nunes, L.C.S. (2011). Determination of young's modulus in polyester $\mathrm{Al}_{2} \mathrm{O}_{3}$ and epoxy $\mathrm{Al}_{2} \mathrm{O}_{3}$ nanocomposites using the digital image correlation method. Composites Part A: Applied Science and Manufacturing, 43, pp. 304-309.

[20] Vivek, G., Joanna, P., Ryan, P.S., Andrew, J., Krzysztof, M., Ramanan, K. (2018). Structure of block copolymer grafted silica nanoparticles, Polymer, pp. 1-38.

[21] Xuechen, T., Hongbin, Y., Yongbo, G., Zeeshan, A. L., Changxiao, C., Wanli, K. (2018). Preparation of a micron-size silica-reinforced polymer microsphere and evaluation of its properties as a plugging agent, Colloids and Surfaces A, 547, pp. 8-18.

[22] Constantinescu, D. M., Dragos, A. A., Catalin, R. P., Krzysztof, K., Manfred, S. (2017). Mechanical properties of epoxy nanocomposites reinforced with functionalized silica-nanoparticles, Procedia Structural Integrity, 5, pp. 647-652

[23] Guangshun. W., Lichun, M., Li, L., Lei, C., Yudong, H. (2015), Preparation of $\mathrm{SiO}_{2}-\mathrm{GO}$ hybrid nanoparticles and the thermal properties of methylphenylsilicone resins/SiO2-GO nanocomposites, Thermochimica Acta, 613, pp. 77-86.

[24] Ebrahimi, F. and Mahmoodi, F. (2018), Vibration analysis of carbon nanotubes with multiple cracks in thermal environment, Advances in Nano Research, 6(1), pp. 57-80.

[25] Wu, F., Zhang, S., Chen, Z., Zhang, B., Yang, W., Liu, Z. (2016), Interfacial relaxation mechanisms in polymer nanocomposites through the rheological study on polymer/grafted nanoparticles. Polymer, 90, pp. 264-275.

[26] Madani, K., Mokhtari, M., Belhouari, M. and Hannani, M. (2013). Effect of Modifying the Edges of the Adherends and the Adhesive on the Stress Distribution over the Width and Length of Recovery, Case of a Single Lap Joint, International Journal of Mining, Metallurgy \& Mechanical Engineering (IJMMME), 1(4).

[27] Juliana Primo Basílio, D.S. and João Marciano Laredo, D.R. (2014). A Thermomechanical and Adhesion Analysis of Epoxy $/ \mathrm{Al}_{2} \mathrm{O}_{3}$ Nanocomposites Nanomater Nanotechnol, pp. 5-18.

[28] Lim Sheau, H. (2010). Synthese and Micro-Mechanical Properties of Epoxy-Alumina Nanocomposites, National University of Singapore.

[29] Kinloch, A., Mohammed, R., Taylor, A., Eger, C., Sprenger, S., Egan, D. (2005). The effect of silica nano particles and rubber particles on the toughness of multiphase thermosetting epoxy polymers, Journal of Materials Science, 40, pp. 5083-5086.

[30] Dittanet, P. (2011). Fracture Behavior of Silica Nanoparticle Filled Epoxy Resin. Theses and Dissertations. pp. $10-34$. 